\title{
Implementation of prevention of parent-to-child transmission (PPTCT) programme in a rural tertiary referral centre - an evaluation of three years
}

\author{
Bharat Talukdar, Karabi Barman, Hemkanta Dev Sarma \\ Correspondence: Dr Bharat Talukdar, Assistant Professor, Department of Obstetrics and \\ Gynaecology, FAA medical College and Hospital, Barpeta, Assam, India; Email - \\ talukdarbharat@gmail.com
}

Distributed under Creative Commons Attribution-Share Alike 4.0 International.

\begin{abstract}
Objective - The main objective of the study was to evaluate the implementation of PPTCT programme along with the study of feto-maternal outcome of seropositive women. Method - All pregnant women attending antenatal clinic and those attending the labor room directly for delivery in the department of Obstetrics and Gynaecology of FAAMC from 1 st January 2011 to 31 st December 2013 were taken. The samples were processed by three rapid tests. In seropositive woman, post test counseling was done regarding the termination or continuation of pregnancy, methods of delivery. Results and ObservationsThe total number of 22384 patients attended and among them 17139 number of patient $(76.56 \%)$ were tested. A steep rise of acceptance of HIV testing from $65.36 \%$ in 2011 to $86.27 \%$ in 2012 was seen but in 2013 again the acceptance decreased to $75.70 \%$. In 2011, no seropositive case was detected but in 2012 and 2013, the numbers of seropositive women were 3 and 6 , and so the prevalence of HIV was $0.04 \%$ and $0.08 \%$ respectively. Eight of the 9 seropositive women were chosen to institutional delivery, all of them were received Nevirapine prophylaxis. Conclusion - To achieve high success rate in implementation of PPTCT programme, it must be backed up by effective counselling and testing, good quality education about HIV specially among the young adult of reproductive age group.
\end{abstract}

Keywords: PPTCT, HIV

Prevention of Parent-To-Child Transmission (PPTCT) is a specific program that provides a comprehensive, family-centered spectrum of support and clinical services along with other public health initiatives, to prevent the transmission of HIV from parents to their baby.

In India the first AIDS case was detected in 1986 and since then all states and union territories has been reported HIV infection. After reporting of AIDS case in 1986, the National AIDS Control Programme was established by the Government of India. Later on National AIDS Control Organisation (NACO) was established under the Ministry of Health and Social Welfare of Government of India to implement this

Received: $17^{\text {th }}$ July 2016. Accepted: $19^{\text {th }}$ January 2017.

Talukdar B, Barman K, Sarma HD. Implementation of prevention of parent-to-child transmission (PPTCT) programme in a rural tertiary referral centre - an evaluation of three years. The New Indian Journal of OBGYN. 2017; 4(1):81-6 
programme. NACO has decided to establish an India where pregnant woman living with HIV has the choice to bring an HIV free baby into the world; has access to Integrated Counseling and Testing Centers (ICTCs), and those affected by HIV, treated with dignity and quality care.

India has a population of 1.2 billion people and around half of population are adults in the sexually active age group. The total number of people living with HIV (PLHIV) in India is estimated at 21.17 lakhs (17.11 lakhs-26.49 lakhs) in 2015 compared with 22.26 lakhs (18.00 lakhs-27.85 lakhs) in 2007. Children (< 15 years) account for $6.54 \%$, while two fifth $(40.5 \%)$ of total HIV infections are among females ${ }^{1}$.

The prevalence of AIDS in India according to NACO in 2013 was 0.27 , which is down from 0.41 in $2002^{2}$. Although the prevalence of HIV infection has a low rate in India but the spread of infection is uneven. The certain part of India have been more affected than others like Manipur is estimated the highest adult HIV prevalence $(0.78 \%)$, followed by Andhra Pradesh $(0.76 \%)$, Karnataka $(0.69 \%)$ and Nagaland $(0.66 \%)^{3}$. But according to the 2010 data for the first time, no state reported the HIV prevalence among ANC attendees of $1.0 \%$ or more. In the north-eastern part of India, the HIV is primarily found amongst injecting drug users and sex workers but in the southern states, the disease spread mainly through heterosexual contact.

Although Assam is a low prevalence state with the latest official estimate $0.07 \%$ but the HIV prevalence rate has increased from $0.04 \%$ in 2007 to $0.08 \%$ in $2012^{4}$. Fakhruddin Ali Ahmed Medical College (FAAMC) caters to population of Barpeta and neighbouring districts in Lower Assam. In view of our information there is no published data about the implementation of PPTCT program in this region. So the study aims to analyze the PPTCT services offered by our teaching institute located in the Barpeta district of lower Assam which also endorsed with ART treatment centre for AIDS/ HIV infected patient.

\section{Methodology}

This study was conducted in the department of Obstetrics and Gynaecology of FAAMC from 1 st
January 2011 to 31 st December 2013, a period of 3 years since the establishment of PPTCT centre in the institution. All pregnant women attending antenatal clinic and those attending the labor room directly for delivery (unbooked cases) were counseled for HIV testing. After counseling informed consent was obtained and blood sample was collected for HIV testing. As per NACO guidelines, the samples were processed by three rapid tests. The first rapid test was used as screening test for HIV antibody. If the first test sample tested positive then second and third rapid tests were done. When all three tests were reactive then the woman was considered as HIV positive (WHO strategy III). In seropositive woman, post test counseling was done regarding the termination or continuation of pregnancy, methods of delivery. Nevirapine $200 \mathrm{mg}$ single dose, orally was given the woman attending labor room with labour pain or $4 \mathrm{hr}$ before surgery for prophylaxis of baby. All neonates were given Nevirapine syrup $0.5 \mathrm{ml} / \mathrm{kg}$ body weight within 72 hours of birth. Lastly, counseling regarding infant feeding and contraception were done. The babies were referred to the Pediatric HIV clinic of the institution for follow up and were tested for HIV status by ELISA at 18 months.

The study is a record based retrospective study of women attending the PPTCT centre of Fakhruddin Ali Ahmed Medical College, Barpeta. During the process of data collection, analysis and publication, confidentiality of the persons concerned were duly respected, and related NACO guidelines were strictly followed.

\section{Results and Observations}

As per table-1 ANC registration had increased from 2011 to 2013 gradually but the percentage of women tested showed a steep rise from $65.36 \%$ in 2011 to $86.27 \%$ in 2012. Again in 2013 the acceptance decreased to $75.70 \%$. From the year 2011 to 2013, the no of women detected positive were 0,3 , and 6 (total 9). Therefore the seroprevalence of HIV was 0, 0.04, and $0.08 \%$ in 2011, 2012, and 2013 respectively and out of them two discordant couples were recorded. Table 2 gives an idea of the sociodemographic profile 
Table 1: PPTCT service in three years

\begin{tabular}{lllll}
\hline Category & $\mathbf{2 0 1 1}$ & $\mathbf{2 0 1 2}$ & $\mathbf{2 0 1 3}$ & Total \\
\hline No of antenatal cases attending OPD & 5278 & 7663 & 9349 & 22384 \\
No of woman tested for HIV & 3450 & 6611 & 7078 & 17139 \\
No of unbook cases accepting test & 155 & 245 & 330 & 730 \\
No of seropositive woman & Nil & 3 & 6 & 9 \\
Percentage of woman accepting the test & $65.36 \%$ & $86.27 \%$ & $75.70 \%$ & $76.56 \%$ \\
No of HIV + ve spouse & Nil & 2 & 5 & 7 \\
No of HIV -ve spouse (discordant couple) & Nil & 1 & 1 & 2 \\
HIV seropositivity prevalence & Nil & $0.04 \%$ & $0.08 \%$ & $0.05 \%$ \\
\hline
\end{tabular}

Table 2: Sociodemographic profile of HIV positive women

\begin{tabular}{llll}
\hline Age & Age in years & Number & Percentage \\
\cline { 3 - 4 } distribution & $20-25$ & 5 & $55.55 \%$ \\
& $>25-30$ & 4 & $44.44 \%$ \\
Occupation & Go & 0 & - \\
& Hovt. servant & 1 & $11.11 \%$ \\
& House wife & 8 & $88.88 \%$ \\
& Daily wage labour & 0 & - \\
Residence & Commercial sex worker & 0 & - \\
& Rural & 9 & $100 \%$ \\
& Urban & 0 & - \\
\hline
\end{tabular}

institution. Table 3 also reflects the mode of delivery. Out of the 8 positive women who delivered in our hospital in the 3 years, 2 delivered by elective LSCS and 6 vaginally. One women did not come back after she was detected positive and she delivered an IUD baby at home. Single dose $200 \mathrm{mg}$ Nevirapine (NVP) was given to all mothers except in the case of intra

Table 3: Therapeutic Intervention of HIV positive women Intervention

Institutional delivery

Home delivery

Vaginal delivery in FAAMCH

Caesarian section

Live birth 20122013 Total

IUD

Antiretroviral prophylaxis to mother

Antiretroviral prophylaxis to neonate

Breast feeding

Artificial feeding

of the seropositive women. Maximum (55.55\%) were of the age group of 20-25 years. Majority (88.88\%) were housewife. All of them reside in rural area. Table 1 shows 9 seropositive women. Out of 9 women who were 3 outlines the course of pregnancy in detected positive in the 3 years, 8 delivered in our uterine fetal death (IUFD). In our study out of the 8 live babies 3 were breast fed and 5 were formula fed.

\section{Discussion}

The total number of 22384 patients attended antenatal OPD from 1 st January 2011 to 31 st December 2013 and among them 17139 number of patient (76.56\%) were tested for HIV. In many other studies, it was found that the acceptance of test range from $36 \%$ to $99 \%{ }^{5-7}$. It was also observed that most of the women attend antenatal OPD without company of their husband. So, some of those patients did not attend for counseling and testing.

This study also reveals that, there was a steep rise of acceptance of HIV testing from $65.36 \%$ in 2011 to 86 . 27\% in 2012. But in 2013 again the acceptance decreased to $75.70 \%$ due to irregular availability of kit 
in the month of March, April, August, September, October and December from the higher authority.

Similarly, the acceptance of test of unbooked case gradually increased to 155, 245 and 330 in 2011, 2012 and 2013 respectively.

In 2011, no seropositive case was detected; but in 2012 and 2013, the numbers of seropositive women were 3 and 6 respectively. Therefore the prevalence of HIV in the year of 2012 and 2013 were $0.04 \%$ and $0.08 \%$ in the study. Although the rise of prevalence was observed from 2012 to 2013 but it did not cross the overall prevalence of the state of Assam which was about $0.08 \%$ in $2012^{4}$. According to Assam AIDS control Society (ASACS) the prevalence rate of HIV in Assam is lower than the National prevalence of $0.31 \%$ ${ }^{8}$. The ASACS also mentioned that the adult HIV prevalence rate has increased from $0.04 \%$ in 2007 to $0.08 \%$ in $2012^{4}$. The rising trend of HIV transmission of the state is because of the following reasons: a) Assam is the gate-way of other Northeastern states, b) the state is surrounded by two high prevalence states that are Manipur and Nagaland, c) large number of female migrants from other Northeastern states, West Bengal, Nepal who come to Assam for employment and take sex work as earning source, d) highprevalence of other sexually transmitted infections, stigma and social discrimination, inequity, high prevalence of risky sexual behaviour among young people, existence of mobile and hidden nature of female sex workers, drug abuse, injecting drug use, illegal drug trafficking, etc are also responsible for increased vulnerability of the state.

In the study an attempt was made to observe the status of the spouse of the seropositive woman. Out of the 9 seropositive women, all spouses were counselled and tested. Among them 2 spouse were found seronegative (discordant couple). All serodiscordant couples were advised to use condom regularly during counselling.

Sociodemographic observation of the seropositive women reveal that most of the women $(88.88 \%)$ are housewife, all residing in rural area, in the age group of $20-30$ years which are comparable to some other studies ${ }^{6,9}$. Mukhopadhyay G. et al found in the study that the awareness towards the HIV is low in the rural residents ${ }^{10}$ due to low level of literacy. Most of the information provided by Govt. is in the form of posters or leaflets and not of much helpful due to illiteracy of the maximum number of rural women.

In the study, it is found that all of the 9 HIV positive women continued their pregnancy till term period of gestation. Among them 8 number of women chose to undergo institutional delivery. Only one woman reported home delivery of an IUD baby. Out of the 8 HIV positive women who were delivered in our institute in 2 years, 2 women delivered by elective LSCS and 6 women delivered vaginally. Post operative period was uneventful for the 2 LSCS patient. Though the overall $25 \%$ of HIV positive women were delivered by elective LSCS but the percentage had increased from $0 \%$ in 2012 to $40 \%$ in 2013 . This percentage of elective LSCS is comparable to other studies ${ }^{10,11}$.

For the prevention of HIV infection in infants and young children, WHO promotes a comprehensive strategic approach which include four components ${ }^{12}$ : a) Primary prevention of HIV infection; (b) Prevention of unintended pregnancies among women living with HIV; (c) Prevention of HIV transmission from mothers living with HIV to their infants; (d) Care, treatment and support for mothers living with HIV, their children and families. The third component can be achieved by using Anti retroviral (ARV) drugs in pregnancy, ensuring safer interventions of delivery, practising neonatal ART and choosing safer feeding practices for baby.

It was found that 8 of the 9 seropositive women who chose to deliver their baby in the institution, all of them received Nevirapine prophylaxis. Nevirapine $200 \mathrm{mg}$ single dose, orally was given to the 6 seropositive women who were attended in labor room for vaginal delivery. In case of other 2 seropositive women who chose the mode of delivery by caesarean method received this prophylaxis for baby 4 hrs before surgery. After delivery, all of the 8 neonates received Navirepine syrup in the dose of $0.5 \mathrm{ml} / \mathrm{kg}$ body weight within 72 hours. In Uganda, all PPTCT drug regimens 
were tested between 1997 and 1999 in the HIVNET 012 trail ${ }^{13}$. In that study, it was found that the rate of HIV transmission from seropositive mother to baby became almost half after giving a single dose of Nevirapine orally to the mother at the onset of labour and to the baby after delivery. This regiment is relatively cheap and easy to administer as it is given only once to the mother and baby. Similarly, Colvin et al ${ }^{14}$ in South Africa and Moodley et al ${ }^{15}$ in some developing countries confirmed the safety and efficacy of this regiment in their studies.

Breastfeeding is not advised in case of seropositive mother and the use of breast milk substitute (formula) is acceptable, sustainable and safe for the baby. Many studies have shown that there are diminished protection benefits of drugs to the neonates when the mother practices breast feeding. But when the mothers live in such a condition where safe drinking water is not available and artificial feeds are expensive then, the risk of life-threatening conditions from formula feeding may be higher than the risk from breastfeeding. For this reason, proper counselling was done regarding the risks and benefits of the breastfeeding and the other methods of infant feeding. In our study, out of 8 seropositive women 3 breast fed their babies and 5 gave formula food. So, majority of women practised formula feeding after proper counselling.

\section{Conclusion}

The follow up of the mother as well as the baby of the seropositive women is difficult due to social stigma and discrimination in the community. So, they must be supported by well trained staff who takes great care to ensure confidentiality about the disease. To achieve high success rate in implementation of PPTCT programme, there must be effective counselling and testing, good quality education about HIV especially among the young adult of reproductive age group. These are also important to eliminate the misunderstanding among the pregnant women regarding the HIV.

\section{Conflict of interest: None. Disclaimer: Nil.}

\section{References}

1.National AIDS Control Organisation. India HIV Estimations 2015 -Technical report. New Delhi; Stationary office: 2015 (Ministry of health \& family welfare government of India).

2.India HIV and AIDS statistics. HIV \& AIDS information from AVERT.org. http://www.avert.org/indiaaids.htm (accessed on 10.07.2015)

3.Annual Report 2010-11. National AIDS Control Organization. Department of AIDS Control. Ministry of Health \& Family Welfare, Government of India. New Delhi; 2011.

4.Assam state AIDS control society. Clinical audit of client data: an analytical report. Dec 2013.

5.Maitra N, Kavishkar AB, Dinkar A, Desai VA. Antenatal HIV Testing. J Obstet Gynecol India. 2006; 56(1): 56-8.

6.Goswami S, Chakravarty PS. Epidemiology of HIV in antenatal women in an urban set up. J Obstet Gynecol India. 2008; 58(2):134-37.

7.Jeve Yadava B,Mishra V.Response to antenatal HIV testing and prevention of parent to child transmission:an experience in a peripheral hospital in India. J Obstet Gynecol India. 2009; 59(2):124-26.

8.Assam State AIDS Control Society [Internet]. Guwahati; 2015. [Cited on 30rd January 2015]. Available from : http://assamsacs.org/introduction.htm

9. Chaudhuri S, Bose S, Talukdar A, Ghosh US.

Seroprevalence and utilization of therapeutic intervention in PPTCT services in a teaching hospital in Kolkata. . J Obstet Gynecol India. 2007. 57(3):251-56.

10.Mukhopadhyay G, Bhattacharya S, Pati S, Biswas N et al. Implementation of PPTCT program in a rural tertiary referral centre - A journey of five years. Journal of evolution of medical and dental sciences. 2013; 2(8): 1393-1401.

11.Goswami S, Chakravorty PS. Prevention of Parent to Child Transmission of HIV (PPTCT): An effort of 4 years in a tertiary centre. J Obstet Gynaecol India. 2011; 61(4): 394- 98

12.WHO. Antiretroviral drugs for Treating pregnant women and Preventing HIV infection in infants: towards universal accessrecommendations for a public health 
approach. World Health Organization, Geneva: Published by WHO Press; 2006.

13.WHO. Nevirapine for the Prevention of Mother to Child Transmission of HIV. WHO reconfirms its support for the use of Nevirapine to prevent mother-to child transmission of HIV; World Health Organization, Geneva: Published by WHO Press, Accessible at http://www.niaid.nih.gov/daids/Prevention.htm.

14.Colvin M, Chopra M, Doherty T, et al. Operational effectiveness of single-dose nevirapine in preventing mother-to-child transmission of HIV. Bull World Health Organ. 2007; 85: 466-73.

15.Moodley D, Moodly J, Coodavia H, et al. A multicenter randomized controlled trial of nevirapine versus acombination of zidovudine and lamivudine to reduce intrapartum and early postpartum mother-to child transmission of human immunodeficiency virus type 1 . J Infect Dis. 2003;187:725-35.

Bharat Talukdar ${ }^{1}$, Karabi Barman ${ }^{2}$, Hemkanta Dev Sarma ${ }^{3}$

${ }^{1}$ Assistant Professor, Department of Obstetrics and Gynaecology, FAA Medical College, Barpeta, Assam, India; ${ }^{2}$ Assistant Professor, Department of Obstetrics and Gynaecology, , FAA Medical College, Barpeta, Assam, India; ${ }^{3}$ Assistant Professor, Department of Obstetrics and Gynaecology, FAA Medical College, Barpeta, Assam, India. 